\title{
Seasonal Variations in Hospital Admissions for ST-Elevation Myocardial Infarction in New Zealand
}

\author{
Janice Swampillai ${ }^{\mathrm{a}, \mathrm{b}}$, Namal Wijesinghe ${ }^{\mathrm{a}}$, Cherian Sebastian ${ }^{\mathrm{a}}$, Gerard P Devlin ${ }^{\mathrm{a}}$
}

\begin{abstract}
Background: Increased numbers of ST Elevation Myocardial Infarction admissions (STEMI) have been observed during winter in many countries. Our aim was to assess if seasonal variation of STEMI was present in the Waikato region of New Zealand.

Methods: Case notes of patients admitted to Waikato hospital with STEMI between July 1998 and December 2007 were analysed. The incidence of STEMI during summer (December to February), autumn (March to May), winter (June to August) and spring (September to November) were calculated. The individuals were divided into 2 age groups of $\leq 70$ and $>70$ years of age.
\end{abstract}

Results: A total of 3,569 patients (mean age $66.9 \pm 14.1$ years, $64 \%$ men) were included. STEMI presentation during winter was significantly higher compared with summer $(35 \pm 13$ versus $27.3 \pm 11.3$ cases per month, $\mathrm{P}<0.02$ ) with 3 additional STEMI admissions per fortnight during winter months. The increase in STEMI in winter was more apparent in patients $>70$ years of age, with an $8.5 \%$ increase in winter admissions compared to summer $(\mathrm{P}<0.01)$. There was no significant difference in the incidence of STEMI between other seasons.

Conclusions: There is a higher incidence of STEMI during winter in the Waikato region compared with summer. This increased incidence is particularly pronounced in patients over 70 years of age. Further investigations are necessary to elicit potential causes.

Keywords: ST elevation myocardial infarction; Seasonal variation

Manuscript accepted for publication September 14, 2012

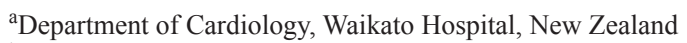

${ }^{\mathrm{b} C}$ Corresponding author: Janice Swampillai, Department of Cardiology, Waikato Hospital, Private Bag 3200, Hamilton 3240, New Zealand.

Email: janiceswampillai@msn.com

doi: http://dx.doi.org/10.4021/cr223e

\section{Introduction}

Winter months show an increased number of ST Elevation Myocardial Infarction (STEMI) admissions in many countries [1-3]. Stroke, pulmonary embolism and aortic dissection also show seasonal variations [4-6]. The exact reason is not clear but may relate to cold weather conditions, stress and increased inflammatory markers due to concurrent respiratory tract infections [7]. Some studies have also suggested that ambient temperature, air pollution, sunlight hours and air pressure may contribute to this phenomenon [8]. Our aim was to assess whether seasonal variation of STEMI exists in the Waikato region in New Zealand.

\section{Methods}

We carried out a retrospective case note analysis of all patients admitted to Waikato hospital with STEMI between July 1998 and December 2007. Seasons were defined as summer (December to February), autumn (March to May), winter (June to August) and spring (September to November). The daily incidence of STEMI during summer, autumn, winter and spring was calculated. The number of days per month was standardised using the following equation: Standardised months $=($ number of cases $/$ days in the month $) \times 30$.

The individuals were divided into 2 age groups of $\leq 70$ and $>70$ years of age. Data on STEMI incidence distribution in the 4 seasons was analysed using the Chi squared test, with the probability value $\mathrm{P}<0.05$ considered to be statistically significant. Mean and minimum monthly temperatures were obtained from the National Institute of Water and Atmospheric Research.

\section{Results}

A total of 3,569 patients (mean age $66.9 \pm 14.1$ years, $64 \%$ men) were admitted to Waikato hospital with STEMI during the study period. The incidence of STEMI was highest in winter (Table 1), and STEMI presentation during winter was 
Table 1. Seasonal Daily Incidence of STEMI in the 2 Age Groups

\begin{tabular}{lllll}
\hline & Summer & Autumn & Winter & Spring \\
\hline Total & 0.95 & 1.02 & 1.14 & 1.05 \\
Age $\leq 70$ & 0.53 & 0.59 & 0.61 & 0.60 \\
Age $>70$ & 0.42 & 0.43 & 0.53 & 0.44 \\
\hline
\end{tabular}

significantly higher compared with summer $(35 \pm 13$ versus $27.3 \pm 11.3$ cases per month, $\mathrm{P}<0.02)$ with 3 additional STEMI admissions per fortnight during winter months (Fig. 1).

The increase in STEMI in winter was more pronounced in patients $>70$ years of age (Fig. 2), with an $8.5 \%$ increase in winter admissions compared to summer $(\mathrm{P}<0.01)$. There was no significant difference in the incidence of STEMI between other seasons.

\section{Discussion}

The Waikato region in the North Island of New Zealand has a temperate climate (Fig. 3), and is situated at latitude 37.47 south, longitude 175.19 east, at $29 \mathrm{~m}$ of altitude. Minimum temperatures range from $13{ }^{\circ} \mathrm{C}$ in summer to $3.9^{\circ} \mathrm{C}$ in winter, and mean sunshine hours vary from 231 hours per month in summer to 103 hours per month in winter [9].

Our study confirms the seasonal variation of hospital admissions for STEMI that has been documented in both hemispheres $[10,11]$. The first correlation between seasons and coronary thrombosis was documented in 1926 [12]. Although other authors have previously demonstrated a variation in coronary heart disease mortality in New Zealand [13], our study is the first to assess hospital admission rates.

We have demonstrated a $6.9 \%$ increase in STEMI admissions in winter compared to summer. This is comparable with seasonal changes observed in other parts of the world.
Winter weather is associated with a number of trigger factors for myocardial infarction, including increased sympathetic tone and blood pressure, myocardial oxygen demand, factors promoting coagulation, blood viscosity, cortisol and cholesterol levels [14]. External and lifestyle factors also contribute, as physical activity, fat and vitamin $\mathrm{C}$ intake, body mass index and smoking patterns have all been shown to alter in winter [15]. In addition to lower ambient temperatures, a reduction in hours of sunshine and vitamin D levels, environmental pollution and atmospheric pressure changes have also been implicated in the increase in myocardial infarctions in winter. Blood glucose and insulin levels are lower in summer in non-diabetic patients [16]. Acute and chronic infections, particularly respiratory tract infections also show an increased incidence in winter, and these concurrent infections are believed to increase infarction rates [7].

Reports from other parts of the world have shown that younger age groups show a spring peak in addition to a winter peak, and we have also observed this trend from our data (Fig. 2) [17]. Winter peaks in mortality from coronary heart disease increase with age. In our population, there was an $8.5 \%$ increase in STEMI admissions in the over 70 year old age group in winter compared to summer. Environmental factors are especially important in older people, and ineffective heating and insulation, lack of warm clothing, poor nutrition and decreased physical activity are likely to be influential.

This study is important to establish that there are seasonal variations in STEMI admission in the Waikato region.

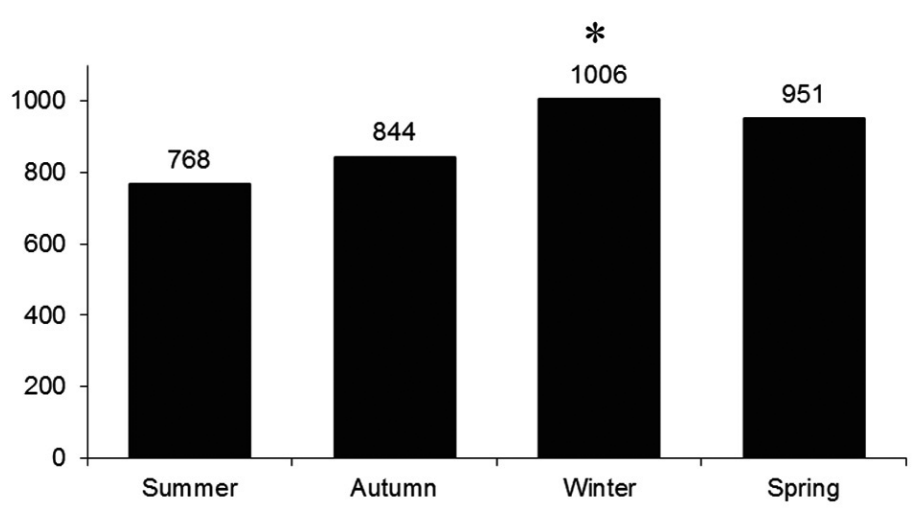

Figure 1. Total number of STEMI admissions during each season, ${ }^{*} \mathrm{P}<0.01$. 


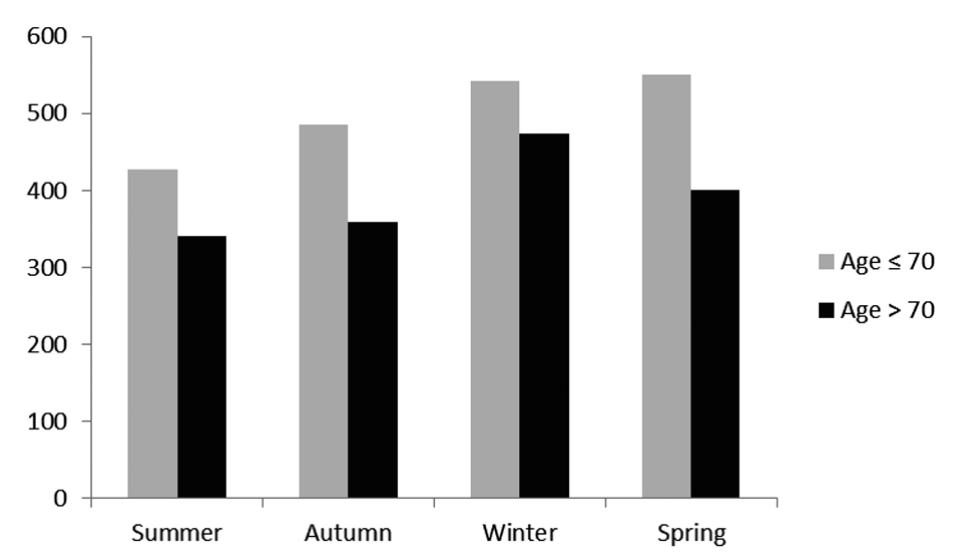

Figure 2. Total number of STEMI admissions in the 2 age groups.

The focus of attention should now be on identifying potentially avoidable triggers in the winter months. In particular, patients with coronary disease should be aware of this seasonal trend, and measures taken to ensure that their lifestyles are as healthy in winter as in summer. The United Kingdom Meteorological Office health forecasting services have been developed in order to limit the impact of weather on people's health and hospital admissions. Healthy Outlook is a preventative service aimed at helping people with chronic obstructive pulmonary disease manage their condition. When particular climatic conditions such as extremes of temperature and humidity are expected, the Met Office's Healthy Outlook service sends an automated phone message to patients, directing them to follow simple health advice designed to help them stay well. This resource enables patients to take appropriate action and plan ahead to reduce the impact of a cold snap that could result in an admission to hospital. A Met Office evaluation found an average national reduction in hospital admissions of $20 \%$ for those using the scheme
[18]. A similar resource could potentially be beneficial in patients with or at risk for coronary heart disease, although this would not impact on those presenting for the first time with a myocardial infarction. Simple safeguards such as wearing warm clothing indoors and outdoors, installing suitable heating and maintaining a healthy diet could help to reduce the incidence of hospital admissions for STEMI in winter. The impact of climate change on seasonal variations of myocardial infarction may influence these patterns in the future.

\section{Limitations}

We have only analysed data from patients admitted to hospital with primary diagnosis of STEMI in our region. As a result we have not included all events in the community. This data does not take into account patients who were hospitalised for other reasons and developed a STEMI during the course of the admission. In addition we have not distinguished between initial and recurrent STEMI, and these may

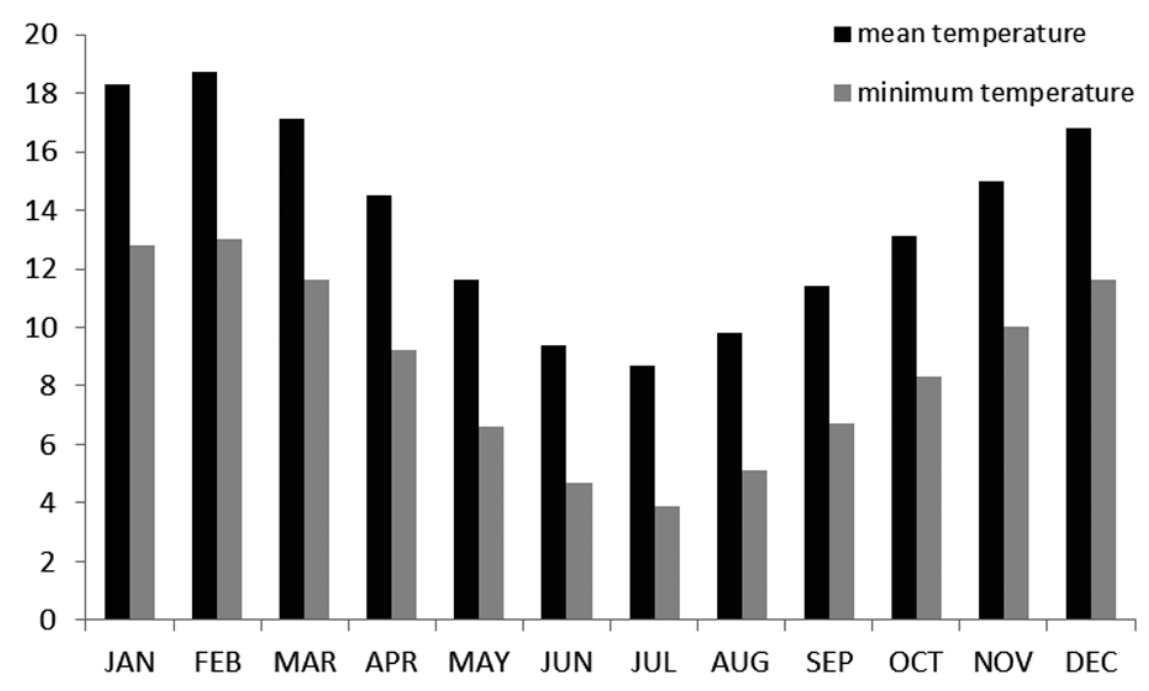

Figure 3. Monthly mean and minimum temperatures $\left({ }^{\circ} \mathrm{C}\right)$ in the Waikato region. 
show different seasonal variations.

\section{Conclusion}

There is a higher incidence of STEMI during winter in the Waikato region compared with summer. This increased incidence is particularly pronounced in patients over 70 years of age. Further investigations are necessary to elicit potential causes.

\section{Conflict of Interest}

None.

\section{References}

1. Bhaskaran K, Hajat S, Haines A, Herrett E, Wilkinson P, Smeeth L. Effects of ambient temperature on the incidence of myocardial infarction. Heart. 2009;95(21):1760-1769.

2. Manfredini R, Manfredini F, Boari B, Bergami E, Mari E, Gamberini S, Salmi R, et al. Seasonal and weekly patterns of hospital admissions for nonfatal and fatal myocardial infarction. Am J Emerg Med. 2009;27(9):10971103.

3. Marchant B, Ranjadayalan K, Stevenson R, Wilkinson $\mathrm{P}$, Timmis AD. Circadian and seasonal factors in the pathogenesis of acute myocardial infarction: the influence of environmental temperature. Br Heart J. 1993;69(5):385-387.

4. Oberg AL, Ferguson JA, McIntyre LM, Horner RD. Incidence of stroke and season of the year: evidence of an association. Am J Epidemiol. 2000;152(6):558-564.

5. Stein PD, Kayali F, Beemath A, Skaf E, Alnas M, Alesh I, Olson RE. Mortality from acute pulmonary embolism according to season. Chest. 2005;128(5):3156-3158.

6. Mehta RH, Manfredini R, Hassan F, Sechtem U, Bossone E, Oh JK, Cooper JV, et al. Chronobiological patterns of acute aortic dissection. Circulation. 2002;106(9):1110-
1115.

7. Gonzalez Hernandez E, Cabades O'Callaghan A, Cebrian Domenech J, Lopez Merino V, Sanjuan Manez R, Echanove Errazti I, Valencia Martin J, et al. [Seasonal variations in admissions for acute myocardial infarction. The PRIMVAC study]. Rev Esp Cardiol. 2004;57(1):1219.

8. Li Y, Du T, Lewin MR, Wang H, Ji X, Zhang Y, Xu T, et al. The seasonality of acute coronary syndrome and its relations with climatic parameters. Am J Emerg Med. 2011;29(7):768-774.

9. National Institute of Water and Atmospheric Research. Available at http://www.niwa.co.nz/.

10. Hopstock LA, Wilsgaard T, Njolstad I, Mannsverk J, Mathiesen EB, Lochen ML, Bonaa KH. Seasonal variation in incidence of acute myocardial infarction in a subArctic population: the Tromso Study 1974-2004. Eur J Cardiovasc Prev Rehabil. 2011;18(2):320-325.

11. Sharovsky R, Ce sar LA. Increase in mortality due to myocardial infarction in the Brazilian city of Sao Paulo during winter. Arq Bras Cardiol. 2002;78(1):106-109.

12. Wolff L, White PD. Acute coronary occlusion. Boston Med Surg J 1926; 195: 13-25.

13. Marshall RJ, Scragg R, Bourke P. An analysis of the seasonal variation of coronary heart disease and respiratory disease mortality in New Zealand. Int J Epidemiol. 1988;17(2):325-331.

14. Pell JP, Cobbe SM. Seasonal variations in coronary heart disease. QJM. 1999;92(12):689-696.

15. Crawford VL, McCann M, Stout RW. Changes in seasonal deaths from myocardial infarction. QJM. 2003;96(1):45-52.

16. Fahlen M, Oden A, Bjorntorp P, Tibblin G. Seasonal influence on insulin secretion in man. Clin Sci. 1971;41(5):453-458.

17. Douglas AS, Dunnigan MG, Allan TM, Rawles JM. Seasonal variation in coronary heart disease in Scotland. J Epidemiol Community Health. 1995;49(6):575-582.

18. UK Met Office. Healthy Outlook COPD Forecast Alert Service. Available at http://www.metoffice.gov.uk/ health/copd_forecasting.html. 